\title{
RELIABILITY AND PROTECTION IN DISTRIBUTION POWER SYSTEM CONSIDERING CUSTOMER-BASED INDICES
}

\author{
J. N. Nweke ${ }^{1, *}$, A. G. Gusau ${ }^{2}$ and L. M. Isah ${ }^{3}$ \\ $\mathbf{1}, \mathbf{2}, \mathbf{3}$, Department of Electrical Engineering TeChnology, Federal PolyteChnic Kaura-Namoda, \\ ZAMFARA STATE, NIGERIA \\ Email addresses: ${ }^{1}$ nwekejohn71@yahoo.com, 2 aliyugarbagusau@gmail.com, \\ 3 dangoggo@gmail.com
}

\begin{abstract}
A stable and reliable electric power supply system is a pre-requisite for the technological and economic growth of any nation. Nigeria's power supply has been experiencing incessant power interruptions caused by a failure in the distribution system. This paper developed a system planning approach as part of the key mitigation strategies for improved reliability and protection of the distribution network. The developed algorithm is tested using $33 \mathrm{kV}$ feeder supplying electricity to Kaura-Namoda, Zamfara State, Nigeria. A customer-based reliability index was used as a tool to evaluate the reliability assessment of the feeder test system. The result showed that alternative 3 gives better results in terms of improvement of the system average interruption duration index (SAIDI), which in turn gives the minimum interrupted energy. Also, it is found that a greater number of sectionalizing switches do not give better results. It is very important to place the sectionalizing switches at a strategic location. If it is located at such points that will facilitate to sectionalize the faulty sections faster and to make the supply available to the unfaulty part of the network. Hence the utility company should apply this mitigation algorithm for system reliability improvement, depending on their needs and requirements. Thus, utilities can optimize network performance and better serve customers by adopting mitigation strategies in addressing trouble-prone areas to achieve a stable and reliable supply
\end{abstract}

Keywords: distribution system; reliability; reliability indices; system performance evaluation; protection system; mitigation algorithms and sectionalizing switches.

\section{INTRODUCTION}

Electric power is a vital element in any modern economy. The availability of reliable power supply at a reasonable cost is crucial for the economic growth and development of a country. Electric power utilities throughout the world, therefore, endeavour to meet customer demands as economically as possible at a reasonable service [1]. To meet customer demands, the power utility has to be improved through upgrading, and effective maintenance of the system infrastructure. Analysis throughout the world shows that around $90 \%$ of all customer reliability problems are due to the problem in the distribution system, hence, improving distribution reliability is the key to improving customer reliability [2]. The Power Holding Company of Nigeria (PHCN) mission is to transmit, distribute, and supply adequate electricity in a safe, reliable, and efficient manner and this has to be accomplished. Contrarily, the intermittent power supply to customers by the Nigerian power system network has become a source of worry to the utility company. Many power systems Engineers have carried out different optimization studies via heuristic, network configuration, integration of renewable energy resources, and coordination of distributed generation aimed at improving the system network

\footnotetext{
* Corresponding author, tel: $+234-806-742-0582$
} 
The studies [3] used genetic algorithm (GA) based optimization to optimally locate FACTS devices Unified Power Flow Controllers (UPFC) and the Thyristor Controlled Series Controllers (TCSC) devices in the Nigeria $330 \mathrm{kV}$ integrated power network for power transfer increase and loss minimization at different active and reactive power loadings. The result showed that there was a reduction in transmission line losses of both active and reactive power, after incorporation of TCSC and UPFC devices optimally into the network This approach of optimization technique which is initiated with random generation of the population always lack accuracy when a high-quality solution is required. Particle swarm optimization (PSO) technique was applied by the authors [4] for the optimal placement of DG in the distribution network of 33 and 69 -bus systems. The paper presented different types of DGs using the PSO technique for active and reactive power compensation to minimize the real power losses in the primary distribution networks. A Genetic Algorithm based optimal size and placement of $D G$ in the distribution network has been proposed [5 - 10]. The GA methods are used to find optimal size and bus location for placing DG using power loss and energy loss minimization in a network system based on bus admittance, generation information, and load distribution of the system.

The authors [11-12] tackled the problem of network reconfiguration to minimize real power loss in the system. They applied a meta-heuristic optimization method to achieve the objective. The algorithm developed predicts the switching pattern for reconfiguration which gives minimum loss and minimum voltage deviation. It also reduces the number of switching operations and at the same time satisfying constraints. Rama Rao et al [13] presented a method of using a plant growth simulation algorithm (PGSA) for radial distribution network reconfiguration. The effectiveness of this proposal was tested on a 69-node radial distribution system. The result, when compared with the genetic algorithm optimization method, showed that PGSA succeeded in finding a global solution with a high probability of approximate solution. Ankur et al [14] proposed a network reconfiguration based on a genetic algorithm that employs the use of graphical user interface (GUI) of MATLAB software. Tests carried on 6-bus, IEEE 14-bus, IEEE 30-bus, and
IEEE 57-bus test systems were successful but the work is more of theoretical assumptions.

In the study [15], a static var compensation (SVC) was conducted on the Nigerian 330kV transmission network with the focus of developing indices for improving the transient stability using an appropriate size to locate SVC within the network. The result showed an improved voltage profile and stability of network but the authors did only consider the optimal size of the DG. Kotamarty et al [16] proposed contingency analysis in the system due to DG location and sizing. The objective function was to find the optimal location and size of DG to minimize voltage deviation from a predetermined profile but the method did not meet the requirement of robustness.

Jokojeje et al [17] carried research on improving the $330 \mathrm{kV}$ Nigeria grid network through static synchronous compensator (STATCOM). In their work, the effect of the application of static synchronous compensator, a FACTS controller was examined on the performance on Nigeria $330 \mathrm{kV}$, a 28-bus power system. Conventional and modified Newton-Raphson based power flow equations describing the steady-state condition before and after compensation was analyzed through the system. Results from the analysis showed that 5 out the 28 buses of the sample system have their voltage magnitudes fell outside the statutory limits of $0.95 \leq$ vi $\leq 1.05$, were improved, and the total system power losses were reduced by $5.88 \%$.

This study proposed the use of mitigation strategies through the development of an algorithm for improving the reliability and protection of the system network. A 33kV feeder network supplying electricity from Gusua to Kaura-Namoda Zamfara state, Nigeria is used as a case study.

\section{METHODOLOGY}

The appropriate placement of protection devices, sectionalizes, and switches in the distribution feeders have a significant impact on reliability improvement and this will be further enhanced by the application of outage mitigation techniques for the distribution system in Nigeria. The Mitigation Techniques like electric or non-electric methods could be used to improve the reliability in the system. Modern automation technologies can reduce contingency margins, improve utilization and economy of operation, and even provide improved scheduling and effectiveness of maintenance and service [1, 
18]. However, they must be applied well, with the technologies selected to be compatible with the system's need and targeted effectively. On the other hand, a non-electric method such as vegetation management, system improvements, crew placement and management, maintenance practices play an important role in improving reliability in the system [19].

\subsection{Value-based reliability planning}

The bid for Power Company to balance between the cost of improving service reliability and quality, and the economic benefits that these improvements bring to customers and this approach is generally known as Value Base Reliability Planning (VBRP). Value-Based Reliability Planning directly takes account of the value of reliability and power quality to customers in assessing the cost-effectiveness of the proposed investment alternatives [20]. In general, VBRP follows the process as shown in Figure 1. This involves the assessment of power quality supply to customers and the application of measures to improve the prevailing conditions. The probability of consumers being disconnected for any reason can be reduced by an increased investment during the planning phase, operating phase, or both and vice versa. It is evident therefore that the economic and reliability constraints can be competitive, and this can lead to difficult managerial decisions at both the planning and operating phases [21]. Despite the above constraints, it is necessary to ensure a reasonable balance in the reliability of the various constituent parts of a power system, i.e generation, transmission, and distribution. Once the distribution systems are planned, designed, and built, they must be continually monitored, adjusted, expanded, and repaired.

\subsection{System planning approach}

A properly co-ordinate protection system is vital to ensure that an electricity distribution network can operate within the preset requirements for the safety of individual items of equipment, operators, customers, and the entire system network. Figure 2 shows the general developed flow chart based on the systematic planning approach of the distribution network. It consists of nine modules which are individual measures, analysis, and planning to improve the system studies and overall reliability of the network.

\subsubsection{Analysis of Load and Generation}

The determination of the required amount of system generating capacity is to ensure an adequate supply. This is an important aspect of power system planning and operation and, it is divided into static and operating capacity requirements. The static capacity area relates to long term evaluation of this overall system requirement, while, the operating capacity area relates to the short-term evaluation of the actual capacity required to meet a given load level.

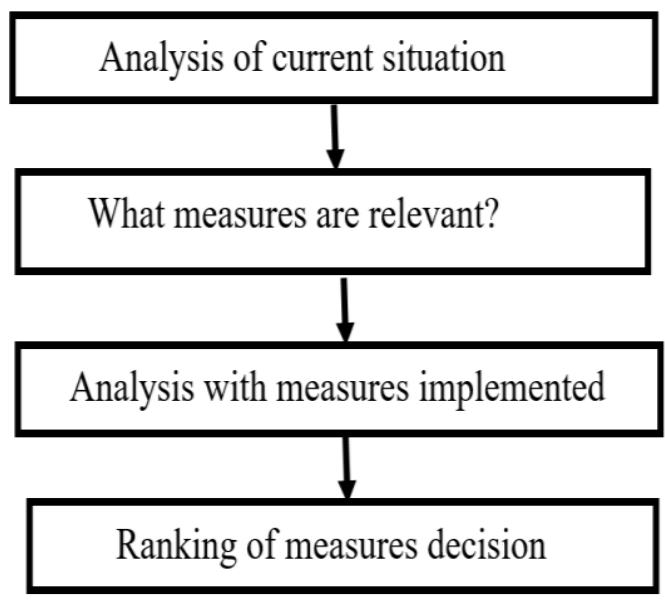

Figure 1: Value-based Reliability Planning

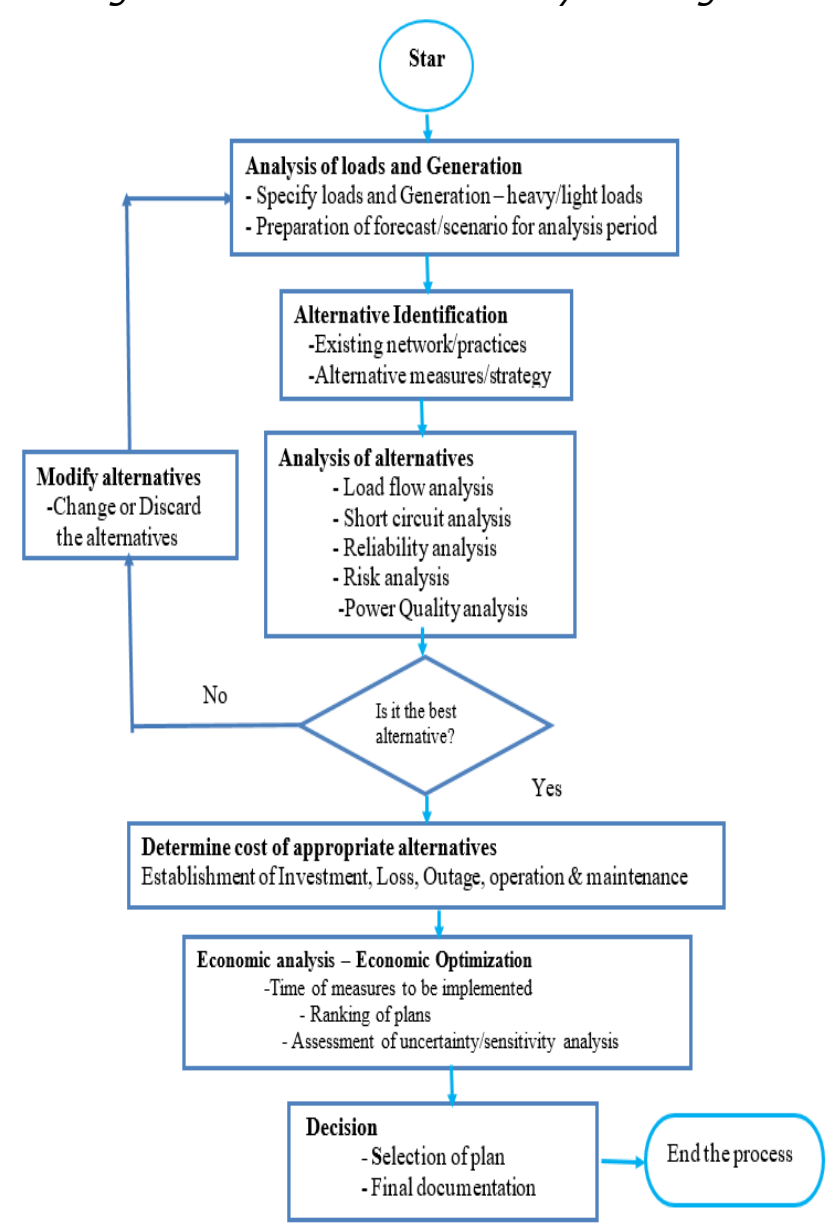

Figure 2: Flow chart for system planning approach of a distribution network

Vol. 39, No. 4, October 2020 


\subsubsection{Identification of alternatives}

This requires a technique where all possible solutions are identified. We can have many possibilities or alternatives in any plan. Based on technical experience, the alternatives which are both technically and economically feasible shall be considered as the existing network solution. This will be taken as a reference solution. As seen from the flow chart, the alternative which does not meet the objective or criteria shall be discarded. Whereas the alternative to maximize reliability makes use of predictive reliability assessment (PRA) for expansion planning. The main advantage of PRA is its ability to forecast the reliability impacts of the system expansion as well as quantify the impact of reliability improvement on the system. Typical improvement options that PRA can address include Load transfers between feeders, new substations and substation expansions, new feeder tie points, feeder automation, replacement of aging equipment, and optimal location of load dispatch centers [22].

\subsubsection{Analysis of the alternative systems}

Network planning and network analysis are often carried out with the help of a computer program that is developed by Power Company. It is one of the basic products of Power Utility Management which is a global software solution that addresses all distribution and transmission requirements. It addresses other issues of load flow analysis, Short circuit analysis, power quality analysis, and economic analysis [1].

\subsubsection{Outage mitigation strategies}

Historical data can be used to quantify improvements and predict the best locations for sectionalizing devices for reliability improvements by adding numbers of recloser at optimal locations. This reduces the system average interruption frequency index (SAIFI) and system average interruption duration index (SAIDI). The location and installation of the number of auto-recloser, switches, load break switches, and sectionalizers help to reduce fault rate, repair time, and sectioning time [23]. The reliability of the system depends on the mitigation techniques being used by the utility namely, electric and non-electric mitigation techniques. It also depends on the need for utility whether it wants to reduce fault rate, repair time, or both or outage duration. After developing the reliability improvement strategy, it is important to apply the interruption mitigation techniques to obtain better results. Hence it is important to analyze the root cause and apply mitigation techniques. The mitigation techniques can be classified into two categories via electrical and nonelectrical method [22]. Electric mitigation techniques have a direct impact on the distribution system and affect the distribution system analysis while non-electric mitigation techniques do not have any impact on other engineering analysis tools and can be evaluated solely with reliability studies. It is, therefore, necessary to apply both the techniques to gain better improvement in the reliability of the system.

\subsubsection{Electric Mitigation Techniques}

These techniques include the addition of protective devices (reclosers and fuses) and switching devices (manual and automated switches), system reconfiguration, and feeder re-conducting. Distribution automation may be the way forward to improve system performance and reliability, reduce cost in the long run, and improve overall customer services. Reclosers have two basic functions on the system, reliability and over current protection and they are mainly used for reliability reasons.

\subsubsection{System Configuration}

A distribution system can be reconfigured by changing the location of the normally open switches. This can also be achieved by effectively changing the allocation of the customers' power flow for the effected feeders. It will not only improve reliability; but also minimizes the losses and operation costs. The basic strategy is to transfer customers presently receiving poor reliability to nearby feeders with better reliability and the effectiveness of this technique primarily depends upon the number of tie switches on the system [24].

\subsubsection{Maintenance Strategy}

It is vital to prioritize maintenance tasks so that the best possible reliability is achieved with increasingly constrained budgets [25]. The main aim of maintenance is to extend equipment lifetime as well as reducing the probability of failure. Maintenance may be divided into two strategies namely;

Vol. 39, No. 4, October 2020

1201 
preventive and corrective maintenance. Corrective maintenance replaces or repairs failed components, while preventive maintenance is a proactive approach to improve the condition of an active component that may be deteriorated to some degree.

\subsection{Reliability Assessment Test on 33kv Feeder System}

The summarized reliability data (2018) for the feeder collected from the Gusau distribution substation Zamfara state is presented Table 1

Reliability indices are statistical aggregations of reliability data from a well-defined set of loads, components, or customers. Several alternatives such as placement of load break switch (LBS), auto reclosers have been used along with the mitigation techniques such as vegetation management and overvoltage protection to evaluate the reliability of a $33 \mathrm{kV}$ feeder installed for power supply to KauraNamoda in Zamfara state of Nigeria shown in figure 3. For reliability analysis of an existing system, the reliability indices are calculated but the predictive reliability analysis of a future system, its reliability indices are interpolated. Reference values are obtained from the values of the best alternative of the previous year in case of predictive analysis, whereas calculated values are obtained based upon the historical data of failures with the number of customers connected and affected by the outage. The following customer-based indices [26] are used to test the $33 \mathrm{kV}$ feeder system.

Table 1: summarized reliability data (2018)

\begin{tabular}{cccccc}
\hline $\begin{array}{c}\text { Outage } \\
\text { Frequency } \\
\text { (no/yr) }\end{array}$ & $\begin{array}{c}\text { Outage } \\
\text { duration } \\
\text { (hrs/yr) }\end{array}$ & $\begin{array}{c}\text { Total number } \\
\text { Customers affected }\end{array}$ & $\begin{array}{c}\text { Total Customer } \\
\text { hours curtailed }\end{array}$ & $\begin{array}{c}\text { Customer } \\
\text { served }\end{array}$ & $\begin{array}{c}\text { Feeder } \\
\text { length (km) }\end{array}$ \\
\hline 20 & 32.43 & 30031 & 48388.45 & 1606 & 100.92 \\
\hline
\end{tabular}

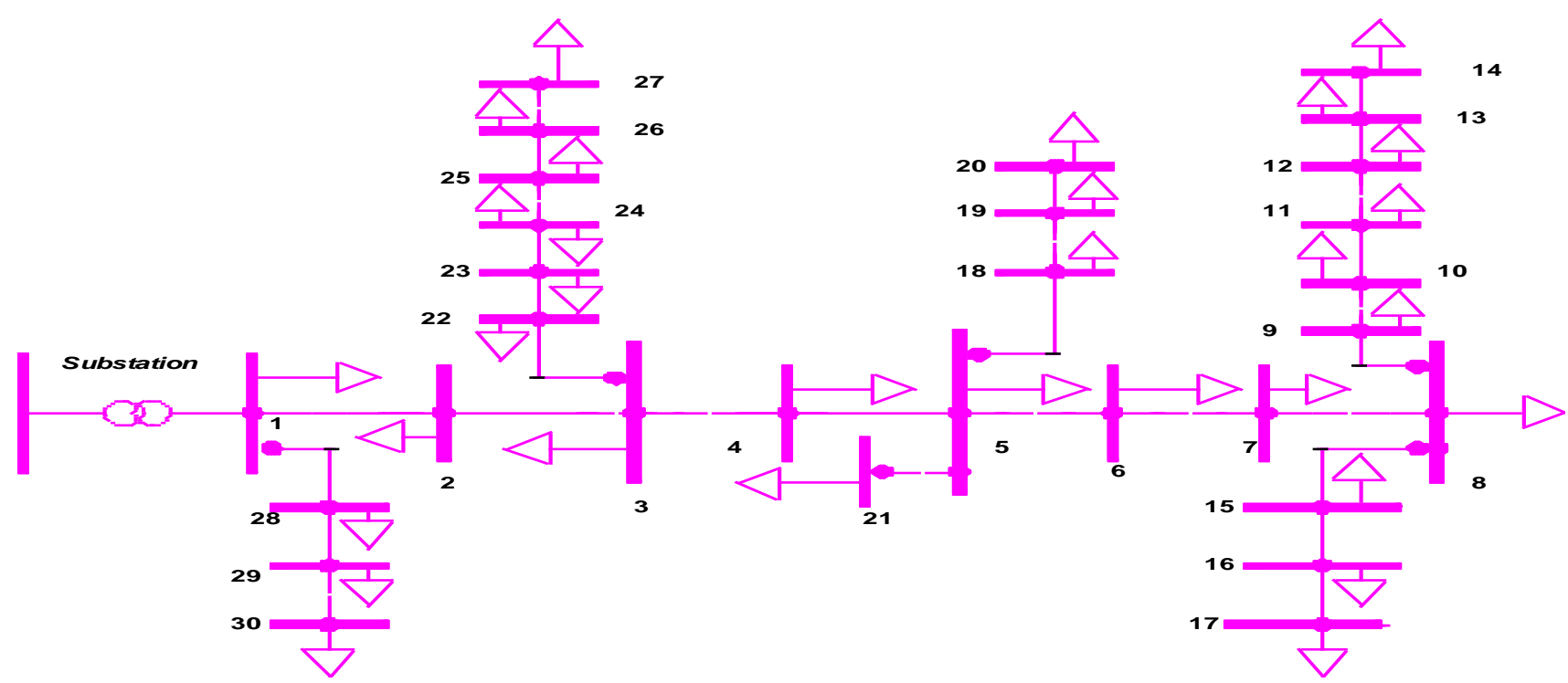

Figure 3: A 33kV feeder system networks

\subsubsection{System Average Interruption Frequency Index (SAIFI)}

This is designed to give information about the average frequency of sustained interruptions per customer over a predefined area.

SAIFI $=\frac{\text { Total number of customer int erruption }}{\text { Total number of customers connected }}=\frac{\sum \lambda_{i} N_{i}}{\sum N_{i}}$

Where $\lambda \mathrm{i}$ is the failure rate and $\mathrm{Ni}$ is the number of customers of load at the ith node.

\subsubsection{System Average Interruption Duration Index (SAIDI)}

This is commonly referred to as customer duration of interruption which is designed to provide information about the average time that the customers are interrupted: 
SAIDI $=\frac{\text { Sumof customer } \text { int } \text { erruption duration }}{\text { Total number of customers connected }}=\frac{\sum v_{i} N_{i}}{\sum N_{i}}$

Where $\mathrm{Ui}$ is the annual outage time and $\mathrm{Ni}$ is the number of customers of load at ith node

\subsubsection{Customer Average Interruption Duration Index (CAIDI)}

This is referred to as the average time needed to restore service to the average customer per sustained interruption.

$$
\text { CAIDI }=\frac{\text { Sumof customer int erruptions duration }}{\text { Total number of customers int erruptions }}=\frac{\sum v_{i} N_{i}}{\sum \lambda_{i} N_{i}}=\frac{\text { SAIDI }}{\text { SAIFI }}
$$

Where $\lambda \mathrm{i}$ is the failure rate, $\mathrm{Ui}$ is the annual outage time and $\mathrm{Ni}$ is customers at ith load point.

\subsubsection{Customer Average Interruption Frequency Index (CAIFI)}

This is designed to show the number of customers affected out of the whole customer base.

CAIFI $=\frac{\text { Total number of customer int errupted }}{\text { Total number of customers connected }}=\frac{\sum v_{i} N_{i}}{N}$

\subsubsection{Average Service Availability Index (ASAI)}

$$
A S A I=\frac{\text { Costomer hours of available service }}{\text { Total hours of demanded }}=\frac{\sum N_{i} \times 8760-\sum v_{i} N_{i}}{\sum N_{i} \times 8760}
$$

\section{RESULTS AND DISCUSSION}

The summary of reliability data (2018) for a 33kV feeder installed to supply electricity to Kaura Nanoda, Zamfara state. The alternatives chosen for the case study is placement and number of Load break switch (LBS) at different locations are listed below;

1. The present system as reference system 2

2. Alt. 1 - Installation of LBS at nodes 3

3. Alt.2 - Installation of LBS at node 4

4. Alt.3 - Installation of LBS at node 5

The reliability results with existing with existing system is shown in table 2 . It is being observed that alternative 3 gives better results in terms of improvement of SAIDI, which in turn gives the minimum interrupted energy. Also, it is found that a greater number of sectionalizing switches do not give better results. It is very important to place the sectionalizing switches at strategic locations, however; it may not be practically true since the location of such switches should be near the motorable roads and the availability of other communication facilities. If it is located at such points, it will facilitate to sectionalize the faulty sections faster and to make the supply available to the unfaulty ones.

\begin{tabular}{|c|c|c|c|c|c|c|}
\hline Indices & Unit & $\begin{array}{c}\text { Calculated } \\
\text { Value }\end{array}$ & $\begin{array}{c}\text { Reference } \\
\text { Value }\end{array}$ & $\begin{array}{c}\text { Alternative } \\
1\end{array}$ & $\begin{array}{c}\text { Alternative } \\
2\end{array}$ & $\begin{array}{c}\text { Alternative } \\
3\end{array}$ \\
\hline SAIFI & Inter/yr & 18.699 & 15.264 & 15.264 & 15.264 & 15.264 \\
\hline SAIDI & h/inter & 30.130 & 26.100 & 25.310 & 25.405 & 25.211 \\
\hline CAIDI & $\mathrm{h} / \mathrm{yr}$ & 1.611 & 1.709 & 1.658 & 1.664 & 1.651 \\
\hline ASAI & $\%$ & 99.66 & 99.702 & 99.711 & 99.710 & 88.712 \\
\hline $\begin{array}{l}\text { Average } \\
\text { Interruption }\end{array}$ & $\mathrm{kWh} / \mathrm{yr}$ & & 13300.90 & 12843.70 & 12892.20 & 12795.30 \\
\hline Peak power & MW & & & 1.035 & & \\
\hline Heaviest loaded line & $\%$ & & & 4.28 & & \\
\hline Max. voltage drop & $\%$ & & & 0.44 & & \\
\hline
\end{tabular}

Table 2 Reliability results with the existing system for the year 2018 


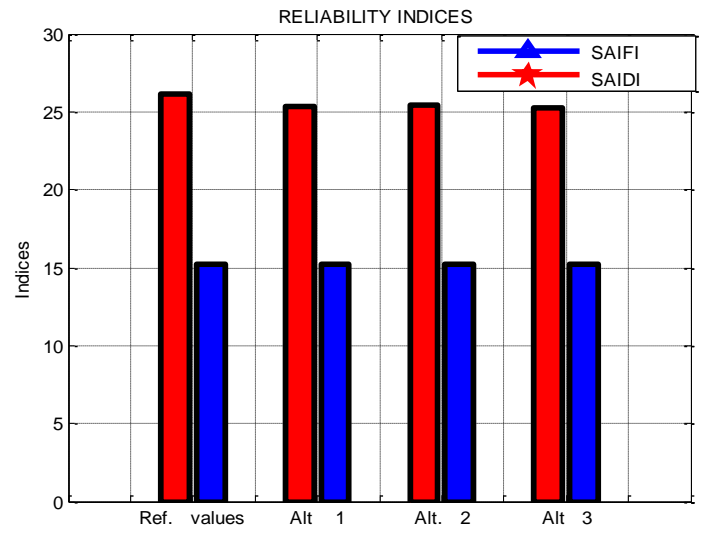

Figure 4: Customer-based reliability indices

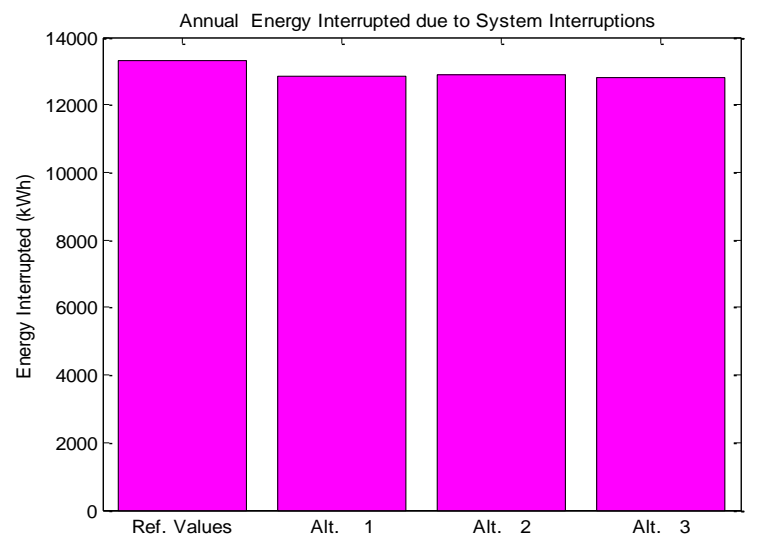

Figure 5 Energy interrupted due to interruption

Figure 4 shows the customer-based reliability indices analysis using SAIFI and SAIDI with different alternative It is found that an Alternative. 3 gives the minimum SAIDI where SAIFI is found to be the same with all the alternatives. Hence, Alt. 3 indicates the best choice for the better performance of the network.

The customer-based reliability indices are measured based on the energy interrupted. Figure 5 shows the energy interrupted due to interruption in the network. The result indicates that Alt. 3 gives less energy interrupted and thus the best alternative for improved reliability.

\section{CONCLUSION}

Developing the reliability improvement strategy is important as well as applying interruption mitigation techniques to obtain improved results. This paper developed a system planning approach as part of the key mitigation strategies for improved reliability and protection of the distribution network. The developed algorithm is tested using $33 \mathrm{kV}$ feeder supplying electricity to Kaura-Namoda, Zamfara
State, Nigeria. A customer-based index via SAIFI, SAIDI, CAIDI, and ASAI were used as tools to evaluate the reliability assessment of the feeder test system. The result showed that alternative 3 gives better results in terms of improvement of SAIDI, which in turn gives the minimum interrupted energy. Also, it is found that a greater number of sectionalizing switches do not give better results. It is very important to place the sectionalizing switches at a strategic location. If it is located at such points that will facilitate to sectionalize the faulty sections faster and to make the supply available to the unfaulty part of the network. Thus, this result gives information to the distribution company on the performance of the power supply to the customers within the assigned area. Thus, there is a need to improve their power supply to the customers. This is because there is a lot of energy lost due to interruption

\section{REFERENCES}

[1] Okorie P.U., Aliyu U. O, Jimoh B., and Sani S. M., "Reliability Indices of Electric Distribution Network System Assessment", Journal of Electronics and Communication Engineering Research, vol. 3, no. 1, Dec.2015, pp. $1-6$.

[2] Brown R. E., "Electric Power Distribution Reliability", $2^{\text {nd }}$ Edition. Cambridge University Press, pp. 94-100, 1998

[3] Eseosa O and Roland U., "Genetic AlgorithmBased Optimal Placement of TCSC and UPFC in the Nigeria 330KV Integrated Transmission Line Network at Different Reactive Power Loadings", Journal of Engineering Science and Technology Review, vol. 6, no. 5, Jan. 2014 pp. $82-89$.

[4] Satish K, Vishal K., and Barjeev T."Optimal Placement of Different Type of DG Resources in Distribution Networks", Electrical Power and Energy Systems,vol. 53, 2013, pp.752-760.

[5] Deependra S., Devender S., and Verma K. S, "GA Based Optimal Sizing and Placement of Distributed Generation for Loss Minimization", International Journal of Electrical and Computer Engineering, vol. 2, no. 8, 2007, pp. $556-562$.

[6] Mithulananthan N., Than O., and Le Van P., "Distributed Generator Placement in Power Distribution System Using Genetic Algorithm to Reduce Losses", Thammasat International Journal of Science and Technology, vol. 9, no.3, Sept. 2004, pp. 55-62,

[7] Soma B. and S. K. Goswami, "Genetic Algorithm based on Optimal Placement of Distributed Generation Reducing Loss and Improving 
Voltage Sag Performance", International Journal on Electrical and Power Engineering, vol. 2, no. 1, 2011, pp. $21-23$.

[8] Rashmi P., Surya P., Geeta K., Khan Z.R, and Komal S., "Optimal Location and Sizing of Generator in Distributed Generation System", International Journal of Innovative Research in Electrical, Electronics, Instrumentation and Control Engineering Vol. 2, no. 3, March 2014, pp.1272- 1277.

[9] Shukla T. N., Singh S. P., and. Naik K. B., "Allocation of Optimal Distributed Generation using GA for Minimum System Losses", Fifteenth National Power Systems Conference (NPSC), IIT Bombay, Dec. 2008, pp.113-118.

[10] Zahra B and. Seyyed M. H, "GA Based Optimal Placement of DGs for Loss Reduction and Reliability Improvement in Distribution Networks with Time-Varying Loads", International Journal of Intelligent Systems and Applications, vol. 4, pp. 2013, $55-63$.

[11] Rajaram R, Sathish K. K, and Rajasekar N., "Power System Reconfiguration in a Radial Distribution Network for Reducing Losses and to Improve Voltage Profile using Modified Plant Growth Simulation Algorithm with Distributed Generation (DG)" Energy Reports, vol. 1, 2015, pp.116 - 122.

[12] Chidanandappa R., Ananthapadmana T., and Ranjith H. C., "Genetic Algorithm-Based Network Reconfiguration in Distribution Systems with Multiple DGs for Time-Varying Loads", Science Direct Proceeding Technology, vol. 21, Aug. 2015, pp. 460 - 467.

[13] Rama Rao P. V.V and Sivanagaraju S., "Radial Network Reconfiguration for Loss Reduction and Load Balancing Using Plant Growth Simulation Algorithm," International Journal on Electrical Engineering and Informatics, vol.2, no. 4, Nov.2010. pp. $266-277$.

[14] Ankur A and Prabodh K., "GUI Based Network Reconfiguration System for Loss Minimization in Distribution Network," International Journal of Science and Research, vol. 4, no. 1, January 2015, Pp. $805-808$.

[15] Ayodele T. R., Ogunjuyigbe, A.S. O. and Alodele O. O., "Improving the Transient Stability of Nigerian 330kV Transmission Network using Static Var Compensator", Nigerian Journal of Technology, vol. 32, no. 1, January 2016, pp. $155-166$.

[16] Kotamarty S, Khushalani S., and Schulz N., "Impacts of Distributed Generation on
Contingency Analysis", Electric Power Resource, vol. 78, no. 9, 2008, pp 1537- 1545.

[17] Jokojeje R A., Adejumobi I A., Mustapha AO, and. Adebisi O I, "Application of StaticSynchronous Compensator (STATCOM) in Improving Power System Performance, A Case Study of the Nigeria 330kV Electricity grid", Nigerian Journal of Technology, vol. 34, no. 3, July 2015, pp. $564-572$.

[18] Northcote-Green J and Wilson R., "Control and Automation of Electrical Power Distribution Systems, Taylor and Francis Group, 2008.

[19] Jibril $Y$ and Ekundayo, K.R., "Reliability Assessment of 33kV Kaduna Electricity Distribution Feeders, Northern Region, Nigeria", Proceedings of the World Congress onEngineering and Computer Science, (WCECS), San Francisco, USA, 23-25, 2013, pp.1- 5.

[20] Michael J, Sullivan B., Suddeth N., Vardell T and Vojdani A., "Interruption Costs Customer Satisfaction and Expectations for Service Reliability", IEEE Transactions on Power Systems, vol.11, no. 2, May 1996, pp. 989 - 995

[21] Billinton R. and. Allan R. N., "Reliability Evaluation of Power System", Tata McGraw-Hill Publishing Company Limited, New Delhi, New York, $2^{\text {nd }}$ edition.2005, pp. 184-205.

[22] Da Silva M.G., Rodrigues A. B, de Castro C. L.C., Neto A.C., Moutinho E.A, Neto N.S.A., and Cavalcante A.B., "Reliability Assessment of Distribution Networks in Brazil Northeast",8th International Conference ond Probabilistic Methods Applied to Power Systems, Iowa State University, September 12-16, 2004, pp 134 - 152

[23] Kjolle G and Sand K., "An Analytical Approach for Distribution System Reliability Assessment", IEEE Transactions on Power Delivery, vol.7, no. 2, April 1991, pp. 729 - 734.

[24] Woczynski E., Billinton R, and Wacker G., "Interruption Cost Methodology and Results- A Canadian Commercial and Small Industry survey", IEEE Transactions on Power Apparatus and Systems, vol. PAS-103, no. 2, Feb. 1984, pp.437- 444.

[25] Wacker G. and Billinton R., "Customer Cost of Electric Service Interruptions" Proceedings of the IEEE, vol.77, no. 6, June 1989, pp.919-930.

[26] Dorji T, "Reliability Assessment of Distribution Systems,A Case Study on Wangdue Distribution System in Bhutan," Master thesis, Norwegian University of Science and Technology, May 2009, Pp 9-16. 